\section{Brief report on cognitive function and corticosteroid therapy in elderly}

\author{
Alberto Castagna, ${ }^{1}$ Giuseppe Coppolino, \\ Carmen Ruberto, ${ }^{1}$ Giovanni Ruotolo, ${ }^{3}$ \\ Ciro Manzo ${ }^{4}$ \\ ${ }^{1}$ Center for Cognitive Disorders and \\ Dementia, Azienda Sanitaria Provinciale \\ di Catanzaro; ${ }^{2}$ Renal Unit, Department \\ of Health Sciences, Magna Graecia \\ University, Catanzaro; ${ }^{3}$ Geriatric Unit, \\ Pugliese-Ciaccio General Hospital, \\ Catanzaro; ${ }^{4}$ Internal and Geriatric \\ Medicine Department Azienda Sanitaria \\ Locale Napoli 3 sud, Rheumatologic \\ outpatient clinic and \\ geronthorheumatologic service, \\ Mariano Lauro hospital, \\ Sant'Agnello (NA), Italy
}

\begin{abstract}
Glucocorticoids (GCs) are drugs commonly used for the treatment of a great number of acute or chronic pathological conditions. In a cross-sectional study we analyze a cohort of elderly patients treated for at least four weeks with a glucocorticoid (GC), exactly prednisone therapy, for a renal or rheumatological condition pointing out on functional, mental and clinical status. The main purpose was to assess change in cognitive performances. Corticosteroids administration also at low dosage in older subjects could enhance cognitive function. This observation should be proved in larger population and underlying mechanisms studied in deep.
\end{abstract}

\section{Introduction}

Glucocorticoids (GCs) are drugs commonly used for the treatment of a great number of acute or chronic pathological conditions. In particular are often the first choice for inflammatory or autoimmune disorders in rheumatological and nephrological field. It's well known that GCs cause, among other side effects, also a significant alteration in behavior reaching in some circumstance personality traits modification and psychiatric events. ${ }^{1}$ Corticosteroid psychosis was the term adopted to describe a rapid and dramatic onset with psychotic and manic symptoms after acute or also chronic administration of
GCs. $^{2}$ In addition, they cause cognitive impairment of different severity from mild cognitive impairment to dementia ${ }^{1,3}$ but except through case-reports or series with few cases the relationship between GCs and cognitive function was less evaluated. In a cross-sectional study we analyze a cohort of elderly patients treated for at least four weeks with a glucocorticoid (GC), exactly prednisone therapy, for a renal or rheumatological condition pointing out on functional, mental and clinical status. The main purpose was to assess change in cognitive performances.

\section{Materials and Methods}

\section{Study population}

Our analysis comprised patients over 65 years old recruited from January to October 2018 starting corticosteroid therapy for a rheumatological or renal condition. Prednisone treatment was a continuous und current daily prednisone medication (between 5 and $25 \mathrm{mg}$ ) for at least 4 weeks. Clinical and laboratories data were collected. The local Ethic Committee approved the study and all patients gave written informed consent. Subjects underwent a geriatric assessment of functional and cognitive status. We excluded subjects with: i) toxic or pharmacological expossure, excessice alcohol use and pre-existing pharmacological treatments associated with cognitive impairment; ii) severe reduction of renal function (estimated glomerular filtration rate (GFR) under $30 \mathrm{~mL} / \mathrm{min}$ stage 4 National Kidney Foundation); iii) tumor.

Patients' history was carefully recorded by interview and confirmed by checking patients' record, also recording drug prescription. Clinical examination, including assessment of BMI and blood glucose, was performed. Blood pressure was measured three times, and the average value was considered for data analysis.

\section{Assessment of cognitive functions}

Cognitive functions were assessed by Montreal Cognitive Assessment (MOCA) a brief screening instrument to detect Mild Cognitive Impairment that assesses multiple cognitive domains including attention, concentration, executive functions, memory, language, visuospatial skills, abstraction, calculation and orientation. ${ }^{4,5}$ Behavioral symptoms were evaluated with Neuropsychiatric Inventory Scale (NPI, score 0-144).

\section{Clinical and laboratories data}

Health status was assessed by the
Correspondence: Alberto Castagna, Center for Cognitive Disorders and Dementia DSS Catanzaro, Azienda Sanitaria Provinciale di Catanzaro, viale Crotone 88100 Catanzaro, Italy.

Tel./Fax: +39.096.17033013.

E-mail: albertocastagna@tiscali.it

Key words: Glucocorticoids; cognitive function; MOCA; elderly.

Funding: there was no funding for this study.

Contributions: AC, GC, CR; GR, CM, literature research; $\mathrm{AC}, \mathrm{CM}$, manuscript conception and writing and critical revisions.

Conflict of interest: the authors declare no potential conflict of interest.

Received for publication: 27 December 2019. Revision received: 24 Janaury 2020.

Accepted for publication: 30 Janaury 2020 .

This work is licensed under a Creative Commons Attribution-NonCommercial 4.0 International License (CC BY-NC 4.0).

${ }^{\circ}$ Copyright: the Author(s), 2020

Licensee PAGEPress, Italy

Geriatric Care 2020; 6:8785

doi:10.4081/gc.2020.8785

Cumulative Illness Rating Scale (CIRS, score 0-14) scoring system that can classify all medical conditions within 14 organ systems: cardiac, vascular, hematological, respiratory, ophthalmological-oto-rhino-laryngological, upper gastrointestinal, lower gastrointestinal, hepatic-pancreatic, renal, genitourinary, musculoskeletal-tegmental, neurological, endocrine-metabolic-breast and psychiatric. ${ }^{6}$ Daily life functions were assessed by Activities of Daily Living (ADL) and Instrumental Activities of Daily Living (IADL). The Medical Outcomes Study (MOS) Sleep Scale assessed sleep outcomes. $^{7}$

Blood samples were taken in the morning before any food intake. Traditional biochemical parameters were measured at baseline in all subjects, following standard methods in the routine clinical laboratory. eGFR was assessed using the Chronic Kidney Disease Epidemiology Collaboration (CKD-EPI) equation ${ }^{8}$ in according with European Renal Best Practice Group guidelines for the management of older patients with CKD. ${ }^{9}$

\section{Statistical analysis}

Statistical analysis was performed using IBM SPSS Statistics 20 and the Prism package (ver. 4.0; GraphPad Software, La Jolla, 
CA, USA) package. The level of significance was set at $p$-values $<0.05$. Continuous variables are expressed as means \pm standard deviations or medians, as appropriate. Comparisons between continuous data were performed by 2-sample $t$ test or analysis of variance for continuous variable.

\section{Results}

Our analysis comprised 40 patients (30 women, 10 men). 33 with a rheumatologic disease and 7 with a primary glomerulonephritis. No racial differences were present in the population. Participants had a mean \pm SD age of $73.90 \pm 8.07$ (ranging from 67 to 82 years old). Tables 1 and 2 show the main demographic, clinical and laboratory characteristics of enrolled patients. Daily life functions were assessed preserved in our population. The MOCA yielded a mean score of $21.38 \pm 4.32$ before treatment (T0) and 24.30 \pm 3.30 after (T1) steroid therapy $(\mathrm{P}<0.000)$. Neuropsychiatric Inventory Scale doesn't change significantly between T0 and T1. Analysis of single MOCA items showed a difference from T0 to $\mathrm{T} 1$ significative in visuospatial/executive domains $(\mathrm{P}<0.000)$, attention $(\mathrm{P}<0.000)$, abstraction $(\mathrm{P}<0.000)$ and Short-Term Memory/Delayed Recall ( $\mathrm{P}=0.001)$, but not significative for orientation and language. MOS Sleep Scale showed not significant differences.

\section{Discussion}

Main findings from this pilot study suggest that low dosages of corticosteroids are able to positively affect cognitive func- tion. In particular we showed significative differences in visuospatial/executive domains, in attention, in abstraction and in short term memory/delayed recall. Among many other well-known systemic effects GCs have a direct action on central nervous system. Endogenous release of GCs, acting on receptors located in different areas of the brain, control sleep-wake cycle, stimulate memory and learning processes and influence moods and hunger regulation. ${ }^{10}$ In literature is documented the appearance of psychic signs after prolonged treatment with corticosteroids. ${ }^{11}$ Acutely enhanced GCs level increases synaptic plasticity and facilitate hippocampal-dependent cognition while enduring exposure worsens cognition with longlasting detrimental influences on hippocampal function, including altered adrenal steroid receptor density, neurotransmitter content and dendritic atrophy. ${ }^{12,13}$ GCs could act eliciting specific brain area with changes in glutamate release. The downstream effect resulting from GCsGlutamate receptors interaction could be specific of neuronal populations and possibly individual neurons. There is evidence that acute increases of GCs and chronic stress decrease synaptic glutamate reuptake and clearance. ${ }^{14}$ Acute and chronic stress stimuli differ in GCs exposure length (from hours to days to weeks), and investigations into whether this differentially modulates neurotransmission are ongoing. ${ }^{15,16}$ Regarding the significative positive effect of GCs on memory in our population, acutely administered glucocorticoid are known to dose-dependently enhance memory consolidation ${ }^{17}$ but as De Quervain et al. previously demonstrated, a single administration of cortisone $(25 \mathrm{mg})$ $1 \mathrm{~h}$ before retention testing impairs free recall of words that have been learned $24 \mathrm{~h}$ earlier. ${ }^{18}$

\section{Conclusions}

In this pilot study, we investigated patients treated with low to moderate doses of prednisone, widely used in clinical practice. Corticosteroids administration in older subjects could enhance cognitive function. This observation should be proved in larger population and underlying mechanisms studied in deep.

Table 1 Main demographic, clinical and laboratory characteristics of enrolled patients

\begin{tabular}{lc} 
Variable & $(\mathrm{n}=40)$ \\
Age (years) & $75.8 \pm 5.04$ \\
Gender $(\mathrm{M} / \mathrm{F})$ & $10 / 30$ \\
\hline Body mass index $\left(\mathrm{kg} / \mathrm{m}^{2}\right)$ & $26.48 \pm 2.61$ \\
Systolic BP $(\mathrm{mmHg})$ & $144 \pm 10.6$ \\
\hline Diastolic BP $(\mathrm{mmHg})$ & $72 \pm 10.1$ \\
Creatinine $(\mathrm{ng} / \mathrm{dL})$ & $1.19 \pm 0.20$ \\
\hline Serum albumin $(\mathrm{gr} / \mathrm{dL})$ & $3.11 \pm 1.24$ \\
\hline
\end{tabular}

Table 2. Cognitive and physical health parameters before T0 and after (T1) therapy.

\begin{tabular}{lccc} 
Variable & T0 $(n=40)$ & T1 & NS \\
Cumulative Illness Rating Scale (CIRS) & $27.9 \pm 4.90$ & $7.1 \pm 3.8$ & NS \\
NPI & $6.0 \pm 5.3$ & $18.10 \pm 4.7$ & $<0.0001$ \\
\hline MOS Sleep Scale & $18.23 \pm 3.7$ & $24.30 \pm 3.30$ & NS \\
MOCA score* & $21.38 \pm 4.32$ & $4.95 \pm 1.19$ & 0,001 \\
\hline Orientation & $4.82 \pm 1.10$ & $3.9 \pm 1.10$ & $<0.0001$ \\
Short-Term Memory/Delayed Recall & $3.2 \pm 1.12$ & $3.9 \pm 0.95$ & NS \\
\hline Executive Function/Nisuospatial Ability* & $3.32 \pm 0.99$ & $2.7 \pm 0.46$ & $<0.0001$ \\
Language Abilities & $2.8 \pm 0.40$ & $1.25 \pm 0.54$ & NS \\
Abstraction* & $0.82 \pm 0.78$ & $2.35 \pm 0.48$ & $<0.0001$
\end{tabular}

*P statistically significant. 


\section{References}

1. Manzo C, Serra-Mestres J, Castagna A, Isetta M. Behavioral, Psychiatric, and Cognitive Adverse Events in Older Persons Treated with Glucocorticoids. Medicines (Basel) 2018;5(3) [Epub ahead of print].

2. Lewis A, Fleminger JJ. The psychiatric risk from corticotrophin and cortisone. Lancet. 1954;266:383-6.

3. Coppolino G, Bolignano D, Gareri P, et al. Kidney function and cognitive decline in frail elderly: two faces of the same coin? Int Urol Nephrol 2018;50: 1505-10.

4. Nasreddine ZS, Phillips NA, Bédirian $\mathrm{V}$, et al. The Montreal Cognitive Assessment, MoCA: a brief screening tool for mild cognitive impairment..J Am Geriatr Soc. 2005 Apr;53(4):695-9. Erratum in: J Am Geriatr Soc 2019;67: 1991.

5. Conti S, Bonazzi S, Laiacona M, et al. Montreal Cognitive Assessment (MoCA)-Italian version: regression based norms and equivalent scores. Neurol Sci 2015;36:209-14.

6. Parmelee PA, Thuras PD, Katz IR, Lawton MP. Validation of the
Cumulative Illness Rating Scale in a geriatric residential population. J Am Geriatr Soc 1995;43:130-7.

7. Allen RP, Kosinski M, Hill-Zabala CE, Calloway MO. Psychometric evaluation and tests of validity of the Medical Outcomes Study 12-item Sleep Scale (MOS sleep). Sleep Med 2009;10:531-9.

8. Levey AS, Stevens LA, Schmid CH, et al. A new equation to estimate glomerular filtration rate. Ann Intern Med 2009; 150:604-12.

9. Farrington K, Covic A, Aucella F, et al. Clinical Practice Guideline on management of older patients with chronic kidney disease stage $3 \mathrm{~b}$ or higher (eGFR $<45 \mathrm{~mL} / \mathrm{min} / 1.73 \mathrm{~m} 2$ ). Nephrol Dialysis Transplant 2016;31:ii1-ii66.

10. Ciriaco M, Ventrice P, Russo G, et al. Corticosteroid-related central nervous system side effects. J Pharmacol Pharmacother 2013;4:S94-8.

11. Benyamin RM, Vallejo R, Kramer J, Rafeyan R. Corticosteroid induced psychosis in the pain management setting. Pain Physician 2008;11:917-20.

12. Joels M. Corticosteroid actions in the hippocampus. J Neuroendocrinol 2001;13:657-69.

13. McEwen BS, Magarinos AM. Stress and hippocampal plasticity: implica- tions for the pathophysiology of affective disorders. Hum Psychopharmacol 2001;16:S7-S19.

14. Bagley J, Moghaddam B. Temporal dynamics of glutamate efflux in the prefrontal cortex and in the hippocampus following repeated stress: effects of pretreatment with saline or diazepam. Neuroscience 1997;77:65-73.

15. Herman JP, Spencer R. Regulation of hippocampal glucocorticoid receptor gene transcription and protein expression in vivo. J Neurosci 1998;18:7462-73.

16. Shaqura M, Li X, Al-Madol MA, et al. Acute mechanical sensitization of peripheral nociceptors by aldosterone through non-genomic activation of membrane bound mineralocorticoid receptors in naive rats. Neuropharmacology 2016;107:251-61.

17. Buchanan TW, Lovallo WR. Enhanced memory for emotional material following stress-level cortisol treatment in humans. Psychoneuroendocrinology 2001;26:307-17.

18. De Quervain DJ, Roozendaal B, Nitsch $\mathrm{RM}$, et al. Acute cortisone administration impairs retrieval of long-term declarative memory in humans. Nat Neurosci 2000;3:313-4. 